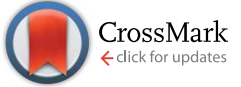

Cite this: RSC Adv., 2016, 6, 99809

\title{
Soluble silicon patterns and templates: calcium phosphate nanocrystal deposition in collagen type $1 \uparrow$
}

\author{
G. Birdi-Chouhan, ${ }^{a}$ R. M. Shelton, ${ }^{b}$ J. Bowen, ${ }^{c}$ P. Goldberg-Oppenheimer, ${ }^{a}$ \\ S. J. Page, ${ }^{d}$ J. V. Hanna, ${ }^{d}$ A. Peacock, ${ }^{e}$ A. J. Wright ${ }^{e}$ and L. M. Grover ${ }^{\star a}$
}

Patterned mineralisation is a feature of many hard-tissues. The impressive mechanical properties exhibited by such tissues can be, in part, attributed to the patterned deposition of mineral within the organic matrix. Although not thermodynamically favourable, the deposition of calcium phosphate based mineral within collagen fibres occurs in vivo in bone and dentine. As a consequence, numerous researchers have investigated how matrix proteins may be conditioned to enable patterned mineral deposition to recapitulate the structures found in nature. In this study, we have demonstrated that this patterned mineralisation of collagen type I may be induced simply by the pretreatment of the collagen with orthosilicic acid (OSA). The OSA treatment of the collagen resulted in a structural change to the collagen fibres, modifying the fibril diameter and changing the kinetics of fibre formation. NMR demonstrated that the OSA was preferentially located at the termini of the procollagen fibrils, thereby templating the formation of apatitic calcium phosphate crystals within the collagen fibrils (as shown using TEM, EDX and SAED). This work demonstrates how simple inorganic ions can have potent effects on structuring biological precipitates and suggests why trace quantities of silicon ions are essential to the formation of healthy hard tissues.

Received 4th August 2016

Accepted 27th September 2016

DOI: 10.1039/c6ra19784a

www.rsc.org/advances

\section{Introduction}

The essential role of silicon in bone biology was first reported by Carlisle (1974) and Schwarz et al. (1972). They demonstrated that decreasing the levels of silicon to a critical level $(<0.5 \mathrm{wt} \%)$ in chick $^{1}$ and rat $^{2}$ diets resulted in bone and cartilage deformations, whereby the bone did not ossify and so remained flexible. Silicon is present in vivo at $0.5 \mathrm{wt} \%$ within newly forming bone (osteoid). This association has led to speculation that soluble silicon, orthosilicic acid (OSA), may play a role during the early stages of mineralized tissue formation indirectly, through its interaction with connective tissues. ${ }^{3}$ Indeed, it was hypothesized that OSA interacts directly with the glycosaminoglycan network within these tissues, through the formation of silanoate ( $\mathrm{R}-\mathrm{O}-\mathrm{Si}-\mathrm{O}-\mathrm{R})$ cross-links that were critical to the stability of the maturing tissue. ${ }^{4}$ In the forty years since this hypothesis was made, there has been no further proof that demonstrates that such interactions exist or that they are

${ }^{a}$ School of Chemical Engineering, University of Birmingham, Birmingham, B15 2TT, UK.E-mail: l.m.grover@bham.ac.uk

${ }^{b}$ School of Dentistry, University of Birmingham, Birmingham, B4 6NN, UK

${ }^{c}$ Department of Engineering and Innovation, The Open University, Milton Keynes, MK7 $6 A A, U K$

${ }^{d}$ Department of Physics, University of Warwick, Coventry, CV4 7AL, UK ${ }^{e}$ School of Chemistry, University of Birmingham, Birmingham, B15 2TT, UK

$\dagger$ Electronic supplementary information (ESI) available. See DOI: 10.1039/c6ra19784a essential to tissue structure. More recent work has focused exclusively on how soluble silicon influences the cells that are found in the newly forming tissue and has largely ignored its role in organizing and manipulating the structure of the extracellular matrix. Soluble silicon has been shown to stimulate human osteoblasts and osteoblast-like cells to secrete type I collagen and other bone markers related to osteoblast maturation and bone formation. ${ }^{5,6}$ Even though silicon has been shown to increase the osteogenic characteristics of osteoblasts, the precise role and localization of silicon remains unclear in bone biology. Numerous studies have also demonstrated that the substitution of silicon into biomaterials used for bone reconstruction can enhance bone formation in the site adjacent to the implant material..$^{7-9}$ As a consequence, a number of materials are now commercially available that are designed to deliver silicon to the implant site in vivo. ${ }^{10}$

Bone is a tissue that is structured at the nano-scale and comprises collagen fibrils into which calcium phosphate nanocrystals are deposited at $67 \mathrm{~nm}$ intervals termed hole zones. ${ }^{11}$ It is this nanoscale organisation that is responsible for the highly impressive toughness and strength of mineralised bone. ${ }^{12,13}$ Interestingly, however, collagen fibrils alone are unable to template patterning of such regular deposits of calcium phosphate. When collagen gels are left in a saturated solution of calcium and phosphate ions, mineralization will occur on the surface of the fibrils as opposed to within the fibrillar structure itself. ${ }^{14}$ The lack of deposition of calcium 
phosphate mineral within these "hole-zones" has been attributed to the fact that deposition of mineral within the collagen fibril is thermodynamically unfavourable..$^{15} \mathrm{~A}$ number of noncollagenous proteins (NCPs) that could potentially overcome this thermodynamic barrier and stimulate intrafibrillar deposition $^{16-18}$ have been identified. These NCPs have been shown to mediate mineral deposition within the collagen fibril and maintain the amorphous nature of the calcium phosphate initially during deposition onto the collagen fibril. ${ }^{16}$ This enhancement in the stability of the amorphous phase has been hypothesised to be one of the factors responsible for enabling intrafibrillar precipitation to take place. ${ }^{19}$ Attempting to mimic this process in vitro through the use of negatively charged small molecules such as poly(aspartic acid), generated intrafibrillar deposition through the formation of a polymer induced liquid precursor (PILP) that may have diffused into the fibril..$^{20}$ More recently, it has been reported that simply making the collagen gels basic (pH 8.5) resulted in an increase in the anionic nature of the collagen and may cause local deamination of the collagen fibril. This in-turn generates a further local reduction in $\mathrm{pH}$ and may drive the deposition of the calcium phosphate nanocrystals within the collagen fibril. ${ }^{21}$ It is worth noting that all of these processes require the use of high concentrations of the component molecules to stimulate template mineralization. Although understanding of bone formation has improved, it remains unclear precisely how and why silicon species seem to be critical to the process. We hypothesise that the role of silicon in bone is not limited to stimulation of osteoblasts to secrete more collagen, ${ }^{5}$ but could be as a consequence of the patterning of the collagenous matrix by orthosilicic acid. We propose that soluble silicon induces patterned mineral deposition in collagen fibrils and serves as a precursor by preparing the collagen template for intrafibrillar apatite deposition.

\section{Results and discussion}

Initially, viability and proliferation studies were carried out on populations of MC-3T3-E1 cells cultured in the presence of 5 and $20 \mu \mathrm{g} \mathrm{ml} l^{-1}$ of OSA. Cell viability was significantly $(p<0.05)$ higher when cells were cultured with $5 \mu \mathrm{g} \mathrm{ml}^{-1}$ OSA on day 7 and 10 , when compared with untreated cells and reached $100 \%$ confluency by day 14 . Cells cultured with $20 \mu \mathrm{g} \mathrm{ml} \mathrm{m}^{-1}$ showed a decrease in cell viability from day 7 , this was considered as the maximum dose for MC-3T3-E1 cell survival (Fig. S1 $\dagger$ ). Furthermore bone nodule formation was evaluated using Alizarin Red-S staining. Following 14 days of culture in the absence of osteogenic mediators such as, ascorbic acid, $\beta$-glycerophosphate and dexamethasone, mineral was noted in all specimens (Fig. 1a). It was particularly noteworthy, that larger and more intensely stained mineral nodules were formed in the absence of OSA rather than in its presence. Indeed when the same threshold was applied, using Image-J to each sample using the most intense staining of the control specimen as 100 , there appeared to be a larger area of mineral formation in the control sample as opposed to treated specimens (Fig. 1b). Superficially it appeared that the OSA inhibited bone nodule formation in these cell cultures. Quantitative analysis of the dissolved stain from the

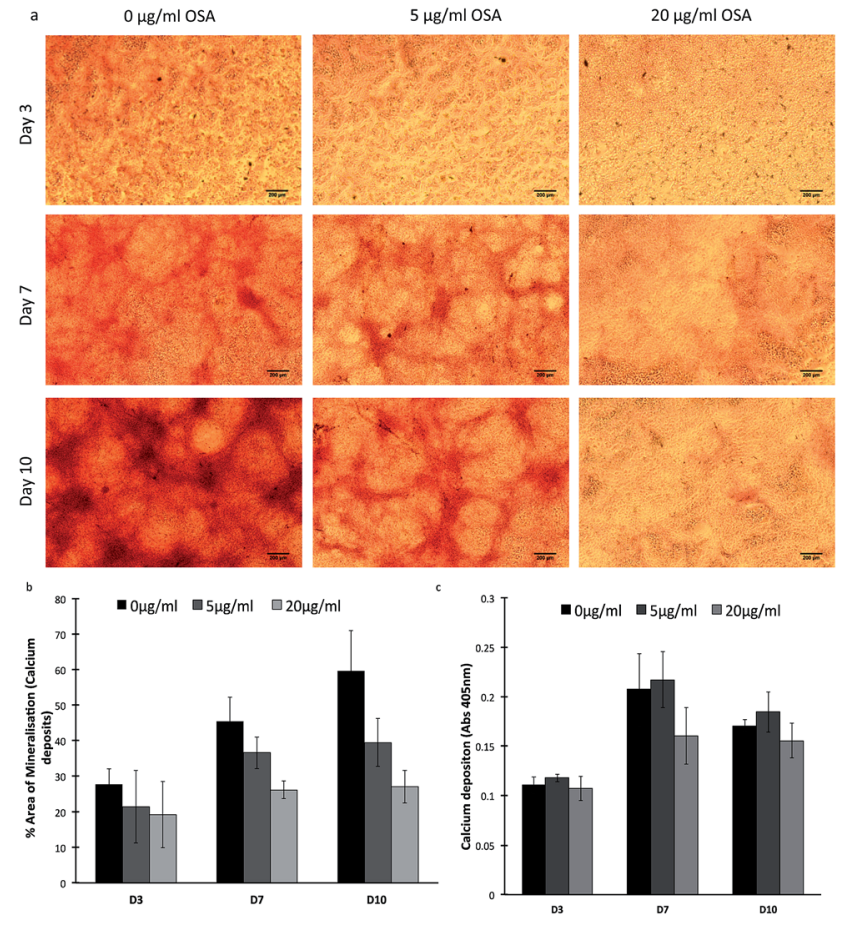

Fig. 1 Bone mineral formation was determined using Alizarin Red-S staining in MC-3T3-E1 cultured in the presence of 0,5 and $20 \mu \mathrm{g} \mathrm{ml}^{-1}$ OSA. An increase in staining was noted in cultures with $5 \mu \mathrm{g} \mathrm{m}^{-1}$ OSA when compared with cultures containing $20 \mu \mathrm{g} \mathrm{ml}^{-1}$ OSA. Scale bar denotes $200 \mu \mathrm{m}$. Semi quantitative analysis (a) indicated that mineral formation was decreased in the presence of OSA. Absorbance measurements (b) after dissolving the stain indicated that there was little difference in total mineral deposition in the different samples when normalized against DNA content.

cultures, however, demonstrated that there was little difference in the quantity of mineral present in each specimen at each time point when normalized against total DNA content (Fig. 1c). It has previously been shown that in the presence of silicon, calcium phosphate $(\mathrm{CaP})$ nodule formation is reduced on the surface of osteoblast cells, but instead mineral deposits are noted on the periphery and within the collagen matrix..22

Thus suggesting that the OSA itself may be involved in mediating the deposition of mineral across the collagen fibrils, giving the impression of a more evenly distributed mineralization of the collagen matrix. Von Kossa staining, used to determine phosphate deposition, also confirmed that the presence of mineral was highest in $5 \mu \mathrm{g} \mathrm{ml}^{-1}$ OSA treated samples when compared to untreated samples (Fig. S2 $\dagger$ ). A significant increase $(p<0.05)$ in mineral deposition was seen in the presence of $5 \mu \mathrm{g}$ $\mathrm{ml}^{-1}$ OSA when compared to the control. The highest concentration of OSA in the samples showed to inhibit mineral deposition (Fig. S3†). To confirm this observation, samples were ashed at $600{ }^{\circ} \mathrm{C}$ and weighed to determine the mass of noncombustible mineral that was present in each culture. Little difference in mineral mass was observed between the samples, suggesting that mineral was present in all OSA containing samples as well as the control (Fig. 2). The presence of mineral in the cultures indicated that the mineral deposition within the cell cultures treated with OSA was of greater homogeneity than 
in the case of the non-treated specimens, where mineralization was concentrated in fewer discrete sites (Fig. 1c)

Transmission electron microscopy (TEM) analysis was carried out on collagen gels formed in the presence and absence of OSA medium for $24 \mathrm{~h}$, the gels were added to TEM girds, washed thoroughly with deionised water and left to air dry. The collagen fibrils that had been left in medium for $24 \mathrm{~h}$ demonstrated no banding that is typical of mineral deposition (Fig. 3a) and the only sign of mineral was at the surface of individual fibrils and took the form of large and irregular deposits. In stark contrast, the addition of $5 \mu \mathrm{g} \mathrm{ml}^{-1}$ of OSA (Fig. 3b) to the collagen resulted in the production of intensely and regularly banded collagen fibrils with a periodicity of approximately $70 \mathrm{~nm}$, typical of mineralized bone matrix. The composition of the banded material was determined using selected area electron diffraction (SAED) (Fig. 3d), which suggested that the deposited mineral was apatitic in nature (Fig. 3e-f). This banding arrangement was identical to naturally mineralized type 1 collagen and often attributed to the role of matrix phosphoproteins, which act as templates for the growth of apatite nucleation and growth within the gap zones of collagen fibrils. ${ }^{23}$ The addition of OSA appeared to replicate the priming of the collagenous matrix for the deposition of the localized mineral.

It has previously been hypothesized that a soluble OSA precursor infiltrates the collagen fibrils and condense along the collagen triple helix creating multiple negative silonal groups within the fibrils. This anionic environment within the fibrils sequesters amorphous CaP from the surrounding environment, which is small enough to infiltrate the silicified collagen. In this way the CaP phases are deposited over the original amorphous silica phase. ${ }^{24}$ Sodium tripolyphosphate (TPP) a linear tripolyphosphate, that has a similar structure to that of OSA, was demonstrated to induce hierarchal mineralization within selfassembling collagen fibrils. TPP forms ionic cross-links (ionic bridges) within collagen molecules leading to the deposition of mineral within the fibrils..$^{22}$ Thus it can also be proposed that OSA may form ionic cross-links with the collagen as a reversible

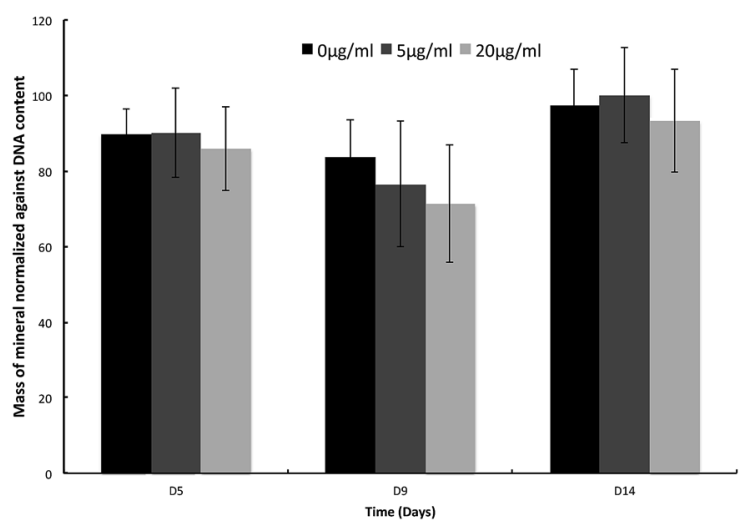

Fig. 2 The amount of mineral present in samples with 0,5 and $20 \mu \mathrm{g}$ $\mathrm{ml}^{-1}$ OSA was normalized against total DNA content. It was noted that mineral was present in all OSA containing samples when compared to the control, with no significant difference between the samples.

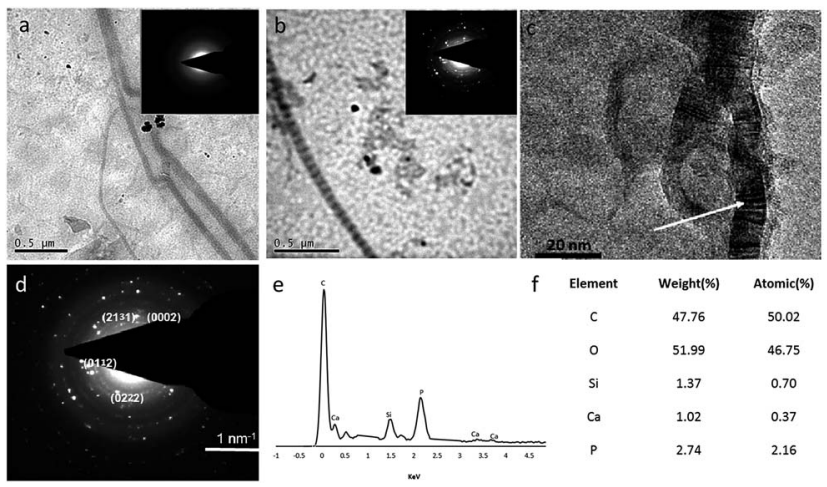

Fig. 3 Unstained TEM photomicrographs of collagen gels formed with and without OSA. Collagen fibrils produced without OSA showed irregular mineral deposition on the surface of the collagen fibrils (a). Inset: selected area electron diffraction (SAED) corresponding with those of poorly-crystalline collagen fibrils containing predominantly amorphous electron-dense minerals. The presence of OSA resulted in organised mineral deposition whereby banding was observed (b) and the SAED demonstrated a crystalline phase within the collagen fibrils (inset). HR-TEM of collagen fibrils in the presence of OSA clearly exhibit electron-dense cross-banding within the collagen fibril (arrowed) (c). The composition of the mineral deposition within the fibrils was determined using SAED and energy dispersive $X$-ray spectroscopy (EDX) and the mineral deposited was apatitic in nature $(d-f)$.

binding mechanism with the remaining - $\mathrm{OH}$ groups contributing to the attraction of amorphous CaP nanocrystals.

Given the striking differences observed between the specimens, the influence of the OSA on the collagen fibril conformation and final diameter was determined using Atomic Force Microscopy (AFM), Circular Dichroism (CD) and turbidity measurements. The addition of OSA to forming collagen gels had a significant influence on the fibril diameter of the collagen shown in Fig. 4 . The addition of quantities up to $50 \mu \mathrm{g} \mathrm{ml} \mathrm{m}^{-1} \mathrm{OSA}$ resulted in a monotonic reduction in fibril diameter and a higher level of fragmentation of the overall structure (Fig. 4b). An increase in diameter when collagen gels were formed with 5$50 \mu \mathrm{g} \mathrm{ml}{ }^{-1}$ OSA could be attributed to expansion of the lateral spaces between collagen molecules to accommodate the infiltration of the mineral phase..$^{22}$

It has been suggested that OSA, dissolved from silicon-based glasses, interacts through hydrogen bonding between the specific sites on the protein helices. On the other hand, concentrated OSA, is mainly constituted of negatively charged poly-silicic acids and these interfere with the assembly of triple helices via electrostatic interactions. ${ }^{25}$ The present study identified a change in morphology of collagen fibrils in the presence of OSA with thicker collagen fibrils forming a more intricate network when OSA was present at concentrations up to $50 \mu \mathrm{g}$ $\mathrm{ml}^{-1}$. It has been suggested that OSA may induce a conformation change in collagen possibly by modifying the hydration state through changes in hydrogen bonding between helices and localized water molecules; this slows the process down and allows for better packing of the triple helices within the fibrils, generating a compact fibril network. ${ }^{26}$ It is likely that this mechanism fully explains how the interactions between the collagen molecules and the OSA resulted in a significant change 

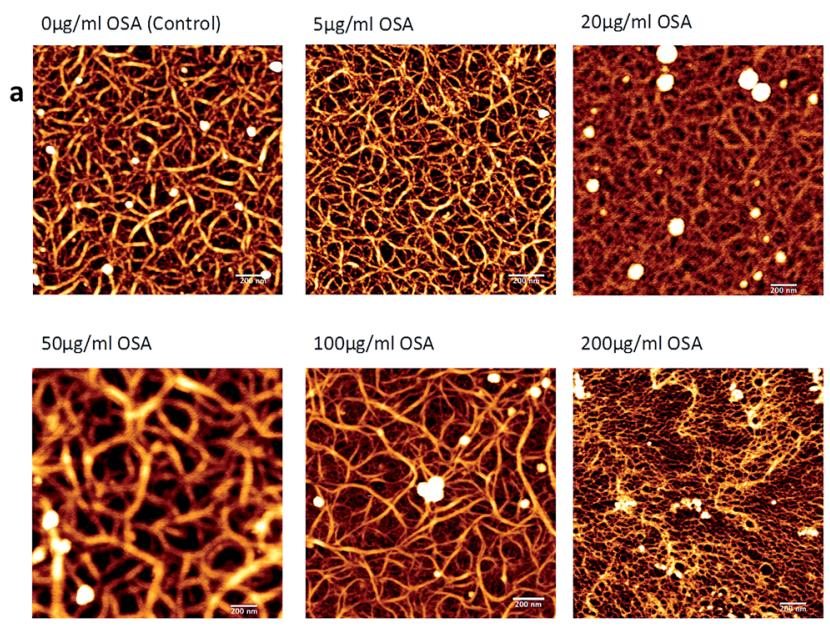

b

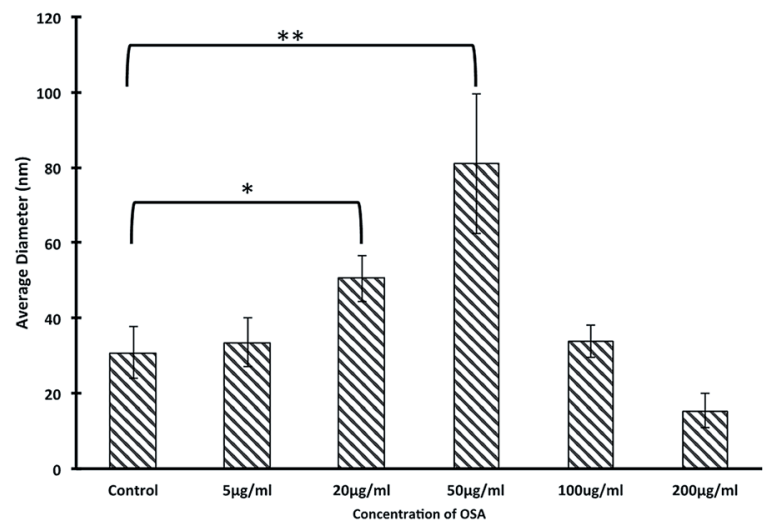

Fig. 4 AFM images of collagen fibrils in the presence of various concentrations of OSA. An increase in OSA concentration altered the collagen network and in supra-physiological conditions (200 $\mu \mathrm{g} \mathrm{ml}^{-1}$ ) OSA completely fragmented the network. Scale bar denotes $200 \mathrm{~nm}$ (a) 20-50 $\mu \mathrm{g} \mathrm{ml}^{-1}$ OSA increase fibril diameter although higher levels of OSA however reduced the fibril diameter (b).

in the morphology of the formed fibrils. ${ }^{27}$ As the concentration of the OSA was increased, fragmentation of the network occurred, and this was also strong evidence of interactions occurring between the OSA and the collagen fibrils. The ${ }^{13} \mathrm{C}$ and ${ }^{29} \mathrm{Si}$ solid state MAS NMR data from the specimens that were treated with OSA demonstrated the nature of this interaction (Fig. 5). A characterization of the collagen structures using ${ }^{13} \mathrm{C}$ MAS NMR (Fig. 5a) shows that with increasing OSA concentration, there was a monotonic reduction in the ${ }^{13} \mathrm{C}$ resonances ascribed to the carboxylic acid functionalities at $\sim \delta 170 \mathrm{ppm}$. These formally quantitative data show that polycondensation is largely complete with the Si speciation in the $100 \mu \mathrm{g} \mathrm{ml}^{-1}$ OSA sample being dominated by $\mathrm{Q}_{4}$ linkages; this concentration of OSA was the only sample sufficiently concentrated enough to afford a signal-to-noise level that was able to be reliably deconvoluted. This indicated that the OSA molecule interacted with the terminal moieties of the collagen fibril, thus suggesting the creation of a bonding arrangement, which promoted ordered mineralization. In contrast, the more qualitative ${ }^{29} \mathrm{Si}$ CPMAS NMR (Fig. 6b) exhibits an inferior (rather than enhanced) signal-to-noise level despite the polarization transfer

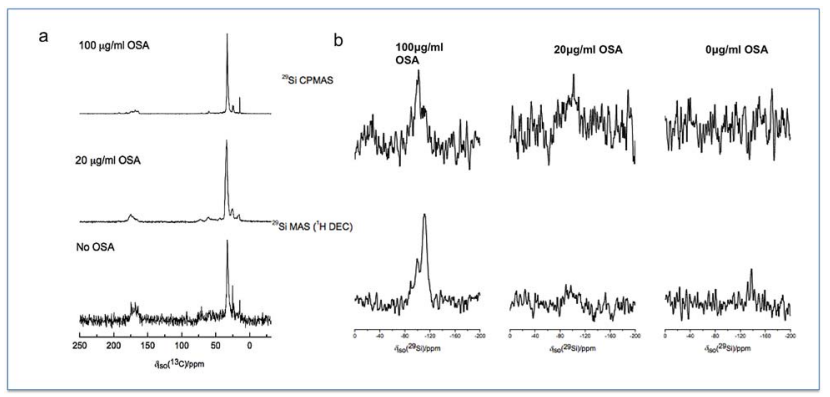

Fig. $5{ }^{13} \mathrm{C}$ NMR spectra on OSA/collagen samples indicative of a monotonic reduction in the ${ }^{13} \mathrm{C}$ resonances ascribed to the carboxylic acid functionalities at $\sim \delta 170 \mathrm{ppm}$ showed that the OSA molecule is interacting with the terminal moieties of the collagen fibril (a) and ${ }^{29} \mathrm{Si}$ NMR spectra on the same samples demonstrated condensed mineral phase as the ${ }^{1} \mathrm{H}-{ }^{29} \mathrm{Si}$ dipolar interaction becomes modulated and reduced (b).

from the more abundant/higher $\gamma^{1} \mathrm{H}$ species. This occurrence suggested that highly mobile water molecules were solvating the condensed mineral phase and the ${ }^{1} \mathrm{H}^{29} \mathrm{Si}$ dipolar interaction was modulated and reduced. These finding are of significant importance since it finally elucidates why ionic $\mathrm{Si}$ is essential for patterned mineralisation, and it also demonstrates how simple inorganic molecules can have a major influence on

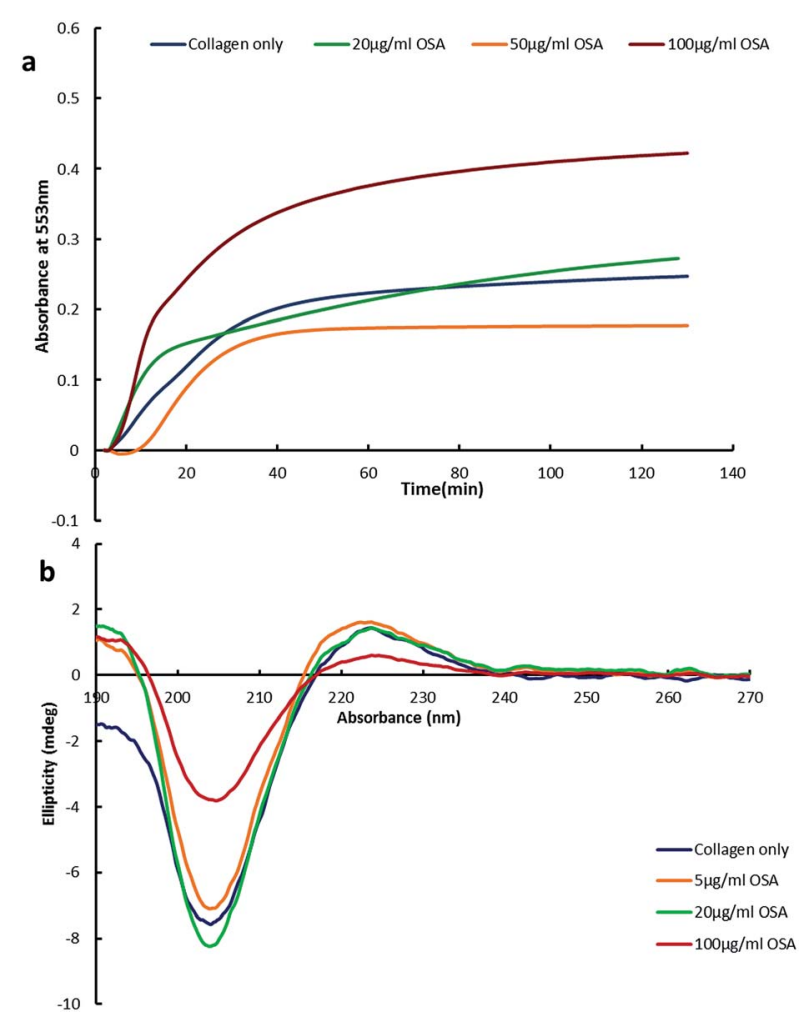

Fig. 6 Turbidity measurements of collagen self-assembly with various concentrations of OSA (a). OSA demonstrated a strong influence on the kinetics of collagen fibril formation. CD spectra of collagen formed with different concentration of OSA showed an increase in intensity when collagen gels were formed with 5 and $20 \mu \mathrm{g} \mathrm{ml}^{-1}$ indicative of an increase in the triple helicity of the structure (b). 
Table 1 CD parameters for collagen formed with various concentrations of OSA. $R_{\text {pn }}$ values are a ratio of absolute positive peak intensity over negative peak intensity

\begin{tabular}{llll}
\hline $\begin{array}{l}\text { Concentration } \\
\text { of OSA }\end{array}$ & $\begin{array}{l}\text { Maximum } \\
\text { ellipticity }\end{array}$ & $\begin{array}{l}\text { Minimum } \\
\text { ellipticity }\end{array}$ & $R_{\mathrm{pn}}$ values \\
\hline $0 \mu \mathrm{g} \mathrm{ml}^{-1}$ OSA & 1.44 & -7.57 & 0.19 \\
$5 \mu \mathrm{g} \mathrm{ml}^{-1}$ OSA & 2.42 & -7.10 & 0.34 \\
$20 \mu \mathrm{g} \mathrm{ml}^{-1}$ OSA & 1.33 & -8.24 & 0.40 \\
$100 \mu \mathrm{g} \mathrm{ml}^{-1}$ OSA & 2.02 & -3.81 & 0.53
\end{tabular}

extracellular matrix structure which subsequently regulates tissue function.

To further elucidate how the OSA influenced collagen fibril assembly, turbidity measurements were made and the confirmations of the fibrils were evaluated using circular dichroism. The kinetics of type 1 collagen fibril formation was determined by turbidity measurement as shown in Fig. 6a. The turbidity versus time graphs generated sigmoidal curves with a lag phase before the onset of an increase in turbidity which is indicative of the formation of nano/micro fibrils, followed by a plateau phase resulting in the complete formation of the fibrils. Collagen gels formed with 20 and $50 \mu \mathrm{g} \mathrm{ml}^{-1}$ OSA had increased lag phases when compared to the collagen gels formed with higher concentrations of OSA (Fig. S4 $\dagger$ ). Changes in the lag phase indicate that the effect of OSA on collagen fibril formation is most likely due to a modification of the collagen microfibrils before the onset of the self-assembly process. The changes in absorbance are attributed to the fibril thickness and ultimate turbidity of the collagen. No significant difference was observed in turbidity in the presence of $20 \mu \mathrm{g} \mathrm{ml}^{-1}$ OSA when compared to collagen samples without OSA. A decrease in absorbance in the presence of $50 \mu \mathrm{g} \mathrm{ml}^{-1} \mathrm{OSA}$ is indicative of the formation of thicker fibrils and an increased absorbance in the presence of $100 \mu \mathrm{g} \mathrm{ml}^{-1}$ OSA demonstrates thinner fibrils as seen in the AFM images in Fig. 5.

The triple helical conformation of native collagen shows a CD spectrum characteristic by a positive band at $223 \mathrm{~nm}$ and a negative band at $203 \mathrm{~nm}$, this is in agreement with earlier reported spectra. ${ }^{28}$ Increases in positive intensities were observed in the presence of 5 and $20 \mu \mathrm{g} \mathrm{ml}^{-1}$ OSA (Fig. 6b). It has previously been suggested that an increase in the number of hydroxyl groups results in increased stabilization of the protein structure due to the aggregation of collagen molecules. ${ }^{29}$

The ratio of the positive peak intensity over negative peak intensity $\left(R_{\mathrm{pn}}\right)$ was measured to determine the helicity of collagen in the solution, shown in Table 1 . An increase in $R_{\mathrm{pn}}$ values was noted as OSA concentration increased, which can be caused by conformational changes in the collagen molecule without complete denaturing of the protein. ${ }^{30}$

\section{Experimental}

\section{Alizarin Red-S staining}

Alizarin Red-S staining was used to quantify calcium deposits in cultures. $40 \mathrm{mM}$ Alizarin Red-S (Sigma Aldrich, UK) was prepared and adjusted to $\mathrm{pH} 4.2$ with $10 \%$ (v/v) ammonium hydroxide (Fischer Scientific, UK). The cultures were fixed with $10 \%(\mathrm{v} / \mathrm{v})$ paraformaldehyde for 30 minutes at room temperature and washed with PBS. Alizarin Red-S stain was added to the cultures and left at room temperature for 20 minutes. Excess stain was removed and the cultures were washed with PBS. For quantification of the Alizarin Red-S stain, $800 \mu \mathrm{l}$ of $10 \%(\mathrm{v} / \mathrm{v})$ acetic acid was added to each well and left to stand for 30 minutes. The cells detached from the bottom of the tissue culture plate and were scraped using a cell scraper (Corning Incorporated, USA) and transferred to a $1.5 \mathrm{ml}$ Eppendorf $\circledast$ tube. After vortexing for 30 seconds the samples were heated at $85^{\circ} \mathrm{C}$ for 10 minutes and placed into crushed ice for 5 minutes. The cell slurry was centrifuged at $14000 \mathrm{rpm}$ for 15 minutes and the supernatant removed and transferred to a clean centrifuge tube. $45 \mu \mathrm{l}$ of $0.1 \%(\mathrm{v} / \mathrm{v})$ ammonium hydroxide was added to neutralize the acid. An aliquot of the supernatant was transferred to a 96 well plate and read at $405 \mathrm{~nm}$ using a plate reader (Promega, UK). ${ }^{31}$

\section{Mass of mineral in cell cultures}

MC-3T3-E1 cells were cultured in 6 well plates at a seeding density of $3 \times 10^{5}$ cells per $\mathrm{ml}$ in Dulbecco's Modified Eagle Medium (DMEM) supplemented with 10\% (v/v) foetal bovine serum (FBS), 2.5\% (v/v) 1 M HEPES, 1\% (v/v) $10 \mathrm{mg} \mathrm{m}^{-1}$ penicillin streptomycin and $2.5 \%(\mathrm{v} / \mathrm{v}) 200 \mathrm{mM}$ L-glutamine and left to attach overnight. The following day, supplemented DMEM containing $5 \mu \mathrm{g} \mathrm{ml} \mathrm{m}^{-1}$ or $20 \mu \mathrm{g} \mathrm{m} \mathrm{g}^{-1}$ of sodium metasilicate was added to the cells. Total mineral mass was determined over time, at each time point; cells were washed and scraped from the bottom of the wells using a cell scraper. The cell slurry was collected and heated to $600{ }^{\circ} \mathrm{C}$ in an oven. The remaining mineral was weighed and normalised against DNA content.

\section{Extraction of collagen from rat-tails}

Eight- to 10 week-old, male, 175 to $200 \mathrm{~g}$, Wistar rats (Charles River, Kent, UK), housed with free access to food and water, under a 12 hour dark/light cycle were used for rat tail collagen type 1 extraction. Tissue harvest was performed at the Biomedical Services Unit at the University of Birmingham (Birmingham, UK) in accordance with the Home Office guidelines set out in the 1986 Animal Act (UK) and the University of Birmingham ethical review committee and conformed to the Federation of European Laboratory Animal Associations (FELASA) guidelines. Collagen was extracted from rat-tail tendons by removing the outer skin from the tail and pulling out the tendons using sterile forceps. The tendons were solubilized in $0.5 \mathrm{M}$ acetic acid solution for 48 hours at $4{ }^{\circ} \mathrm{C}$. The solubilized products were sterile filtered and stored at $4{ }^{\circ} \mathrm{C}$. Dialysis tubes were prepared by immersing in ethanol $(50 \% \mathrm{v} / \mathrm{v})$ for 1 hour at $40{ }^{\circ} \mathrm{C}$ in a fume hood, followed by immersing in 10 $\mathrm{mM}$ sodium bicarbonate $\left(\mathrm{NaHCO}_{3}\right) / 1 \mathrm{mM}$ EDTA solution at 40 ${ }^{\circ} \mathrm{C}$ for 1 hour. The dialysis tubes were washed in distilled water for 1 hour and stored at $4{ }^{\circ} \mathrm{C}$ until required. The solubilized rattail extracts were poured into the dialysis tubes and dialyzed 
against DMEM for $24 \mathrm{~h}$ at $4{ }^{\circ} \mathrm{C}$. After dialysis the collagen extract was centrifuged at $10000 \mathrm{rpm}$ for $2 \mathrm{~h}$ at $6^{\circ} \mathrm{C}$ (Beckman Coulter, UK) and the supernatant was transferred to sterile bottles and stored at $4{ }^{\circ} \mathrm{C}$.

\section{Transmission electron microscopy and evaluating mineral deposition in collagen gels}

Transmission electron microscopy (TEM) was performed on collagen gels produced without OSA and with $5 \mu \mathrm{g} \mathrm{ml}{ }^{-1}$ OSA. 1 $\mu \mathrm{l}$ of the gel solution was added to the carbon grids (Agar Scientific, UK) and left to dry for $30 \mathrm{~min}$. the gels were examined using a Jeol 1200EX TEM (Japan) at $80 \mathrm{kV}$. All samples were examined without further staining. In order to evaluate the deposition of mineral within collagen fibrils in the presence of OSA and an acellular environment, collagen gels were produced with or without OSA and incubated at $37{ }^{\circ} \mathrm{C}$. The presence of mineralization was determined using, high resolution transmission electron microscopy (HR-TEM), selected area electron diffraction (SAED) and energy dispersive X-ray spectroscopy (EDX) and the peaks corrected for $\mathrm{Na}$ and $\mathrm{Cl}$. The obtained SAED patterns were analyzed using Digital Micrograph image (Gatan v3.3) processing software and a computer program for the simulation of polycrystalline electron diffraction patterns and phase identification (JECP/PCED). For the TEM imaging corresponding to the SAED, the samples were analyzed using a FEI Technai 20 TEM (LaB6) at an acceleration voltage of 200 $\mathrm{kV}$ in diffraction mode.

\section{Atomic force microscopy analysis}

Collagen fibril morphology was analyzed using atomic force microscopy (AFM) of gels prepared with different concentrations of OSA and swabbed onto clean silicon substrates before gelling of the samples had occurred. The sample was left to air dry for 20 minutes and rinsed three times in distilled water to remove any excess salts. Surface morphology was determined using a NanoWizard II atomic force microscope (JPK Instruments, UK) operating in intermittent contact mode at a tip velocity of $2 \mu \mathrm{m} \mathrm{s}^{-1}$, employing pyramidal tipped Si cantilevers (PPP-NCL, Windsor Scientific, UK). Collagen fibril diameter was determined using a NanoWizard II AFM imaging software (JPK Instruments, UK).

\section{Nuclear magnetic resonance (NMR)}

Both ${ }^{13} \mathrm{C}$ and ${ }^{29} \mathrm{Si}$ MAS NMR measurements were performed at 7.0 T using a Varian/Chemagnetics InfinityPlus spectrometer operating at Larmor frequencies of 75.5 and $59.6 \mathrm{MHz}$, respectively. All experiments were performed using a Bruker 4 mm HX probe which enabled a MAS frequency of $12 \mathrm{kHz}$ to be enabled. The ${ }^{13} \mathrm{C}$ CPMAS measurements implemented an initial ${ }^{1} \mathrm{H} \pi / 2$ excitation pulse of $2.5 \mu$ s duration, a Hartmann-Hahn contact period of $2 \mathrm{~ms}$ and a recycle delay of $2 \mathrm{~s}$. The CP contact was ramped cross-polarisation condition which ranged from $75 \%$ to $100 \%$ of the ${ }^{1} \mathrm{H}$ channel power, and the ${ }^{1} \mathrm{H}$ decoupling nutation frequency during acquisition was $100 \mathrm{kHz}$. All ${ }^{13} \mathrm{C}$ chemical shifts were reported against the IUPAC recommended primary reference of $\mathrm{Me}_{4} \mathrm{Si}\left(1 \%\right.$ in $\left.\mathrm{CDCl}_{3}, \delta 0.0 \mathrm{ppm}\right)$, via an alanine secondary in which the known shift of the $\mathrm{CH}_{3}$ resonance is $\delta 20.5 \mathrm{ppm}$. For ${ }^{29} \mathrm{Si}$ single pulse MAS NMR, flip angle calibration was performed on kaolinite from which a $\pi / 2$ pulse time of $5 \mu \mathrm{s}$ was measured. All measurements were undertaken with a $\pi / 2$ tip angle, a recycle delay of $240 \mathrm{~s}$ and ${ }^{1} \mathrm{H}$ decoupling during acquisition possessing a nutation frequency of $80 \mathrm{kHz}$. The ${ }^{29} \mathrm{Si}$ chemical shifts were reported against the IUPAC recommended primary reference of $\mathrm{Me}_{4} \mathrm{Si}\left(1 \%\right.$ in $\mathrm{CDCl}_{3}, \delta 0.0$ ppm), via a kaolinite secondary in which the resonance has a known shift of $-92.0 \mathrm{ppm} .{ }^{32}$ The corresponding ${ }^{29} \mathrm{Si}$ CPMAS measurements implemented an initial ${ }^{1} \mathrm{H} \pi / 2$ excitation pulse of $4 \mu$ s duration, a Hartmann-Hahn contact period of $5 \mathrm{~ms}$ and a recycle delay of $5 \mathrm{~s}$. This CP contact was also a ramped crosspolarisation condition which ranged from $75 \%$ to $100 \%$ of the ${ }^{1} \mathrm{H}$ channel power, and the ${ }^{1} \mathrm{H}$ decoupling nutation frequency during acquisition was $80 \mathrm{kHz}$.

\section{Collagen fibrillogenesis}

Kinetic analysis of collagen fibril formation was examined in the presence of different concentrations of sodium metasilicate, by measuring the turbidity of the gelling collagen (loss of transparency) over a period of time using spectrophotometry (Cecil Intruments, UK). Collagen gels $\left(3 \mathrm{mg} \mathrm{ml}^{-1}\right)$ were prepared with various concentrations of sodium metasilicate $\left(20 \mu \mathrm{g} \mathrm{ml}^{-1}\right.$, $50 \mu \mathrm{g} \mathrm{ml}^{-1}, 100 \mu \mathrm{g} \mathrm{ml}^{-1}$ ) and the $\mathrm{pH}$ was adjusted to 8.0-8.5 with $1 \mathrm{M} \mathrm{NaOH}$ to promote gelation. $1 \mathrm{ml}$ of the solution was added into a cuvette $(1 \mathrm{~cm})$ before gelling of the samples occurred and turbidity-time profiles were determined at an absorbance of $553 \mathrm{~nm}$ at $37^{\circ} \mathrm{C}$.

\section{Circular dichroism spectroscopy}

Circular Dichroism (CD) spectra were recorded in a $0.5 \mathrm{~mm}$ path length quartz cuvette at $298 \mathrm{~K}$ on a Jasco J-715 spectropolarimeter. Spectra of $0.25 \mathrm{mg} \mathrm{ml}^{-1}$ collagen gel solutions without OSA and different concentrations of OSA were determined. The observed ellipticities in millidegrees were plotted against wavelength $(\mathrm{nm})$. Spectra are an average of 5 scans recorded between $185 \mathrm{~nm}$ and $400 \mathrm{~nm}$ at $200 \mathrm{~nm} \mathrm{~min}{ }^{-1}$ with a continuous feeding of the measuring compartment with high purity nitrogen (99.99\%) to suppress oxygen absorption.

\section{Statistical analysis}

Data was subjected to statistical analysis and were reported as mean \pm standard deviations. Student paired $T$-tests between groups and one way analysis of variance (ANOVA) and Tukey post hoc test were used to determine significant differences between groups with $p<0.05$.

\section{Conclusions}

We have for the first time demonstrated that silicon in the form of orthosilicic acid enhances the role of collagen as a template for the intrafibrillar deposition of apatite, something that is likely critical to the mechanical performance of bone and other mineralized tissues. The OSA was shown to interact with the terminal groups in type I collagen molecules, within the hole 
zones, thus providing a site for ordered mineral deposition to occur. Given the importance of ordered mineralization to the long-term mechanical stability of bone, we believe that this work finally provides a rational explanation for why deprivation of silicon can cause skeletal deformity and its delivery in materials may enhance localized bone growth. Importantly, this work also highlights how even low concentrations of inorganic molecules can have a profound influence on the structural properties of tissues through modification at the molecular and nanoscopic scales.

\section{Acknowledgements}

J. V. Hanna thanks the University of Warwick, EPSRC and the Birmingham Science City for contributions to the solid state MAS NMR instrumentation used in this research. The latter contribution was partially supported through the Birmingham Science City Advanced Materials Project 1: Creating and Characterising Next Generation Materials Project, with support from Advantage West Midlands (AWM) and partial funding from the European Regional Development Fund (ERDF).

\section{References}

1 E. M. Carlisle, J. Nutr., 1976, 106, 478.

2 K. Schwarz and D. B. Milne, Nature, 1972, 239, 333.

3 R. Jugdaohsingh, S. H. C. Anderson, K. L. Tucker, H. Elliott, D. P. Kiel, R. P. H. Thompson and J. J. Powell, Am. J. Clin. Nutr., 2002, 75, 887.

4 K. Schwarz, Proc. Natl. Acad. Sci. U. S. A., 1973, 70, 1608.

5 D. Reffitt, N. Ogston, R. Jugdaohsingh, H. F. Cheung, B. A. Evans, R. P. Thompson, J. Powell and G. Hampson, Bone, 2003, 32, 127.

6 M. Q. Arumugam, D. C. Ireland, R. A. Brooks, N. Rushton and W. Bonefield, Key Eng. Mater., 2003, 32, 869.

7 I. D. Xynos, M. V. J. Hukkanen, J. J. Batten, L. D. Buttery, L. L. Hench and J. M. Polak, Calcif. Tissue Int., 2000, 67, 321. 8 S. Ni, K. Lin, J. Chang and L. Chou, J. Biomed. Mater. Res., Part A, 2008, 85, 72.

9 S. Heinemann, T. Coradin, H. Worch, H. P. Wiesmann and T. Hanke, Compos. Sci. Technol., 2011, 71, 1873.

10 N. Patel, S. M. Best, W. Bonfield, I. R. Gibson, K. A. Hing, E. Damien and P. A. Revell, J. Mater. Sci.: Mater. Med., 2002, 13, 321.

11 Y. Liu, S. Thomopoulos, C. Chen, V. Birman, M. J. Buehler and G. M. Genin, J. R. Soc., Interface, 2014, 11, 835.
12 A. Biswas, I. S. Bayer, H. Zhao, T. Wang, F. Watambe and A. S. Biris, Bionanocomposites, 2010, 11, 2545.

13 I. S. Bayer, A. Ghosh, M. Labriola and A. B. Biris, RSC Adv., 2013, 3, 20315.

14 Y. Wang, T. Azaïs, M. Robin, A. Vallée, C. Catania, P. Legriel, G. Pehau-Arnaudet, F. Babonneau, M. M. Giraud-Guille and N. Nassif, Nat. Mater., 2012, 11, 724.

15 M. D. Shoulders and R. T. Raines, Annu. Rev. Biochem., 2010, 78, 929.

16 L. Chen, R. Jacquet, E. Lowder and W. J. Landis, Bone, 2015, $71,7$.

17 D. E. Rodriguez, T. Thula-Mata, E. J. Toro, Y.-W. Yeh, C. Holt, L. S. Holliday and L. B. Gower, Acta Biomater., 2014, 10, 494.

18 J. Sodek, B. Ganss and M. D. McKee, Crit. Rev. Oral Biol. Med., 2000, 11, 279.

19 A. J. Lausch and E. D. Sone, Biomacromolecules, 2015, 16, 1938.

20 M. J. Olszta, E. P. Douglas and L. B. Gower, Calcif. Tissue Int., 2003, 72(5), 583-591.

21 B. Marelli, C. E. Ghezzi, Y. L. Zhang, I. Rouiller, J. E. Barralet and S. N. Nazhat, Biomaterials, 2015, 37, 252.

22 Y. Liu, Y.-K. Kim, L. Dai, N. Li, S. O. Khan, D. H. Pashley and F. R. Tay, Biomaterials, 2011, 32, 1291.

23 A. George and A. Veis, Chem. Rev., 2008, 108, 4670.

24 L. Niu, K. Jiao, H. Ryou, C. K. Y. Yiu, J. Chen, L. Breschi, D. D. Arola, D. H. Pashley and F. R. Tay, Angew. Chem., 2013, 125, 5874 .

25 D. Eglin, S. Maalheem, J. Livage and T. Coradin, J. Mater. Sci.: Mater. Med., 2006, 17, 161.

26 D. Eglin, K. L. Shafran, J. Livage, T. Coradin and C. C. Perry, J. Mater. Chem., 2006, 16, 4220.

27 S. Heinemann, C. Heinemann, R. Bernhardt, A. Reinstorf, B. Nies, M. Meyer, H. Worch and T. Hanke, Acta Biomater., 2009, 5, 1979.

28 L. Brazdaru, M. Micutz, T. Staicu, M. Albu, D. Sulea and M. Leca, C. R. Chim., 2015, 18, 160-169.

29 B. Madhan, V. Subramanian, J. R. Rao, B. U. Nair and T. Ramasami, Int. J. Biol. Macromol., 2005, 37, 47.

30 R. Usha, R. Maheshwari, A. Dhathathreyan and T. Ramasami, Colloids Surf., B, 2006, 48, 101.

31 C. A. Gregory, W. G. Gunn, A. Peister and D. J. Prockop, Anal. Biochem., 2004, 329, 77.

32 R. K. Harris, E. D. Becker and S. M. C. D. E. Menezes, Pure Appl. Chem., 2001, 73, 1795. 